\title{
Dispossession: The Tenacity of Things ${ }^{1}$
}

David J. Ekerdt

The goal of this chapter is to map the problem of dispossession, that is, the parting of people and their things that occurs at the end of the consumption cycle. As opposed to a focus on expenditure and accumulation, dispossession is one topic among a set that might be encompassed by the concept of dis-consumption, others being such matters as saving (consumption deferred), taxation (consumption diverted to public purpose), or philanthropy (consumption transferred to others). Because dispossession follows upon possession and because possession entails durations of time, the retention and release of belongings is intertwined with the running of the life course. Possessions support growth, maturation, and the role trajectories of life. They do so in ways that may be historically specific to successive cohorts. Their disposal can also be an intergenerational matter. With an eye to age-related features of this topic, the present discussion will address people's motives for possession, occasions for dispossession, and the necessary labor of both.

In any consideration of the coincidence of people and objects, one tends to make a decision to follow one or the other. There is either a world of objects that encounter people, or a world of people sharing it with stuff. Object-centered thinking views things as having a life, a career, an arc, a death, a presence, an absence (e.g., Appadurai, 1986). As one follows the story of the thing, individual people come and go. Object-centered analyses are comfortable with production and consumption being all of a piece because production and consumption are sequential human acts upon the same thing. 
Objects, as they are conveyed through time, are also seen to "call" for social relations: uniting people, discriminating among them, ritualizing their affairs. When disposed, or rubbished, objects may reappear to interact with humans in a new way (O'Brien, 1999).

The other route through this subject matter is people-centered, viewing things as occupants of people's attention, motives, behaviors, and thoughts. Individuals witness a flow of items through their worlds, often without regard to where objects came from and where they go upon being disposed of. The items themselves are secondary to their handlers. In considering the problem of dispossession, I am going to follow the people because person-object relations are central to the problem of disusing things. But theorizing is rarely so tidy, and it is not surprising to be traveling one axis of the intersection of people and things and then find oneself detoured down the other. For the parting of people and things, I also prefer the term dispossession rather than disposal. The two terms seem nearly synonymous, yet the latter connotes the materiality of objects whereas the former suggests a personal disengagement from things that is consistent with a people-centered analysis.

\section{Why Possession?}

Dispossession presumes possession, so having and keeping are matters that require preliminary attention. Not all the goods that a person acquires-by finding, buying, receiving, or creating-become possessions. Many items (e.g., food, cleaning products, newspapers) are used up in short order; experiences (a concert, a cruise) are had and, aside from any souvenirs, they are over. The consumer economy, it has been observed, grows ever more skilled at the provision of merchandise that flees possession-that needs frequent replacement. The lucrative possibilities of replacement consumption occurred early in life to the legendary American troubadour Woody Guthrie, himself not known as a partisan of capitalism (Brower and Guthrie, 2005). Guthrie started out as an itinerant artist, but soon realized that a customer would pay only once for a painting, but patrons could be sold a song performance over and over. From this insight was born a mighty career. 
The popular impression of a disposable, throwaway society, however, needs some tempering. Does the acquisition of new domestic goods routinely mean that the old material is tossed out? Does the old flowerpot go to the rubbish, or is it stacked atop the other old flowerpots? "Out with the old and in with the new" may be goods specific. According to archeological evidence, the composition of flows to landfills over the twentieth century has changed to include a higher proportion of disposable packaging, food waste, and newspapers and magazines, but other categories of waste (e.g., textiles) have maintained a constant proportion (Lucas, 2002). This suggests that people don't readily toss everything, and that a culture of reuse continues in which the "replaced" possessions are perhaps stored, sold, or given away.

The items that become possessions are those that stay long enough to require the "labor" of possession. Kept things are far more than inert lumps of matter. What is kept must be placed, stored, arranged, contained, maintained, cleaned, insured, emotionally invested, and even "animated" in the sense that the possessor attributes to them an inner life. This living-with or living-into can be called cultivation, habituation, cathexis, appropriation, attachment, endowment, singularization, or decommodification (Dant, 1999; McCracken, 1988). Basically, I make the thing over as mine (Kleine and Baker, 2004). This is true to the root meaning of possession, which is based in the word "to sit"- the thing, as it were, settles in. Consumption, thus, often requires additional productive work to realize possession. To say that possessions are objects that are attended to and cared for does not necessarily mean that they are cherished; they could be merely tolerated, be resented, or even be hated. (It is also important to point out that possession is broader than "owning," which is a legal matter.) The essential point is that possession entrains labor on behalf of the things and their environs.

So, goods flow in and out of our lives but some objects stick and, so, we "have things." From here on, I am going to be more careful with language, preferring now the word thing over the word object when talking about possessions. Following the convention of "thing theory," objects are mere materiality, but things are those 
items invested with a subject-object relation (Brown, 2004). The stuff in your closet are objects; the stuff in my closet are things.

Things counted as possessions number far beyond the few items that are typically showcased in studies of possessions and their meaning, belongings such as antiques, curios, collections, and other cherished effects (Csikszentmihalyi and Rochberg-Halton, 1981). Rather, the totality of our things fill the buildings and rooms we live in, attics, garages, storage sheds, basements, automobiles, and gardens. We also keep possessions at our places of employment. You and I are shepherding a convoy of material that includes clothes, furniture, appliances, kitchen and dining utensils, tools, cars and their peripherals, photographs, heirlooms, records, documents, collections, decorations, seasonal displays, hobby materials, sporting goods, electronics, books, things that belong to others, food, plants, jewelry, cosmetics, toilet articles, medications, and pets. Like a Russian doll, possessions themselves contain possessions that contain possessions back to the deepest recesses of drawers and pantry cabinets.

These things are organized and categorized to various extents. One quality of the whole collection is that it reflects consumption according to age, period, and cohort influences. It is a tenet of aging and life-course studies that an individual's status, behavior, values, and identity are shaped by such influences. Accordingly, it follows that consumption should also be shaped by age, period, and cohort membership and that one's store of possessions should have these characteristics inscribed upon them. Advancing age lays down a residue of belongings acquired for successive roles, for bodily care, for self-development, and as gifts. Advancing age also furnishes the time durations within which things are cultivated or fall out of favor. Period effects on possessions come about when goods are historically new and enter households widely within a short span of time (e.g., forms of consumer electronics). Then there are goods acquired when a cohort enters the market for consumer goods at a certain historical moment. The things available at that time, such as books, recorded music, or furniture, can "date" the household if they are not later replaced with new fashions. In the aggregate level, cohorts of (aging) consumers are moving through the life 
course, replacing one another at various stages of life, thus layering the community with the material holdings from their unique historical experience. In all, the store of possessions, no less than the lives of their keepers, is the unique intersection of two dynamisms, individual aging, and historical change (Riley, Foner, and Waring, 1998).

Just to illustrate the density of possessions, I have a small bedside table with a shelf and two drawers. Its unruliness had begun to bother me, so I decided to declutter it and, in so doing, inventory its contents. It literally held hundreds of possessions, including books (20), magazines (21), pens and pencils (17), shoehorns (2), a pair of women's red leather gloves, a bag of old coins, and my father's medals from World War II. Some of these things I cannot imagine parting with, and some I cannot tell you why I have them or where they came from. In one drawer, a bottle of lotion had leaked and a number of things needed washing. Some items I relocated to other parts of the house. It took over two hours to review the lot and make selected decisions about their arrangement or disposition. However, most of the things eventually went right back into the drawers where they came from. The table is still unruly, but I am reconciled to its disorder.

The density of possessions also stymies research efforts to characterize household contents as a whole and even inquire about their collective meaning. How daunting would it be to inventory people's belongings? Gosling and colleagues (2005) have devised an instrument that can itemize and classify the objects in a space. Applying this technique to the dorm or sleeping rooms of college students, it took the research team the equivalent of one person hour to document the contents of each room. And these were only the visible objects, not those contained in drawers, wardrobes, or boxes, which would include, for example, multiple items of clothing or jewelry.

Why do we keep these things? The motives for possession (i.e., the ongoing commitment to the labor of possession - storing, cleaning, animating) are several. Our research on older people and their belongings (Ekerdt and Sergeant, 2006; Ekerdt, Sergeant, Dingel, and Bowen, 2004) has disclosed nine reasons to keep things. These 
will seem familiar because they are also reasons for acquisition, though the basis for acquisition may evolve into different reasons for retention. Shifting motives for possession are a given among observers of this behavior, leading object-centered studies to talk about things having "careers." It is also important to note that multiple motives can buttress the possession of a single thing (Kleine and Baker, 2004). And if one lives with others, there are items about the place whose possession is shared, or even mysterious.

As we see it, the nine reasons for keeping things are as follows.

1. Things seem useful. Everyday utility-now or to come-tops any list of possession motives, lay or scholarly. But things are instrumental to some end and so simple utility hardly exhausts the meaning of a thing. This is also the occasion to say that things have meaning not just in themselves but also in relation to one another. So, I have one shoehorn because it is occasionally useful, but why have I kept a second shoehorn?

2. Things are worth money. This possession motive is hypothetical pending an actual test of the exchange value of things in the marketplace.

3. Things give pleasure. All right, but "tastes" or "personal aesthetics" are a black box that begs for probing, for explanation, which is why the cherished-possession interview technique has been so productive for revealing people's attitudes and values.

4. Things represent us. They remind us who we are (material biography) and tell our story to others as signs, vehicles, and indicators (Belk, 1988).

5. Things conjure the future. Things promise possible futures and possible selves (Markus and Nurius, 1986). I will someday be the smart and learned person who has read the twenty books at my bedside or acted on their contents.

6. Social reciprocity to gift givers. Keeping things is keeping ties, a feature of the social order long observed by anthropologists (Mauss, 1990). The responsibility for doing this (Kleine, Kleine, and Allen, 1995) can make the household display of items more obligatory than aesthetic or sentimental.

7. Responsibility to forbears. This motive is most complex because family and ancestry are layered onto whatever utility, monetary value, or delight might already adhere to the thing. These are things that outlive people, durable and inalienable things whose disposal is unthinkable (Curasi, Price, and Arnould, 2004; Thompson, 1979).

8. Conservation is a virtue. This is a moral compulsion to retain things that are potentially useful to unspecified others. Remarkably, this motive endures in the United States whose citizens in 2006 nevertheless 
generated 251 million tons of municipal solid waste, which comes to 4.6 pounds per person per day. My country annually trashes 9.1 million tons of furniture and furnishings, 8.6 million tons of clothing and footwear, and 1.1 million tons of books (U.S. Environmental Protection Agency, 2008).

9. We keep because we can. We dwell in ever larger containers, where the convenience of storage exceeds the inconvenience of disposition. The size of the American home has increased in the last thirty-five years from an average 1,500 square feet to 2,400 square feet. Is this house not big enough? The U.S. self-storage industry offers nearly 2 billion square feet of rentable space in 45,000 facilities nationwide (Dudley, 2007).

There has been some research suggesting that younger adults value possessions more for their usefulness, whereas older adults prize symbolic value (Csikszentmihalyi and Rochberg-Halton, 1981) but life-stage differences in the valuation of possessions are not well understood. There is also great conviction that the current generation of older people, having come through economic depression and war are frugal, waste nothing, and keep everything. A culture of scarcity has left them attached to their possessions and so inclined to retain things. The elders to come-the postwar cohort-grew up in an economy of relative abundance and so may more readily slough things off. But the next elders also grew up in larger houses in which retention was convenient. And, if material things have been relatively more important for the construction of identity, the Baby Boomers might have plenty of stuff left over from their lifestyle excursions. At any rate, there is at present no reliable technique for measuring multi-faceted possession attachment (in multiple possessions at that) and so speculation about cohort differences in possession rationales has yet to be tested (Kleine and Baker, 2004).

The list above of nine motives for possession could be subdivided into more or collapsed into fewer. The two most generic motives appear to be (1) instrumental control or effectance of one's environment and (2) the symbolization of self and others (Belk, 1988; Csikszentmihalyi and Rochberg-Halton, 1981; Furby, 1978; Richins, 1994). Sartre (1956) argued that that these two could even be collapsed into one; that having is essentially (a way of) 
being in the world. My father's war medals are me remembering; my sunglasses are me managing my comfort. Sartre's ontological insight, "I am what I have," is echoed through empirical research that repeatedly concludes that possessions are fundamental to a sense of identity (Dittmar, 1992). This immediately suggests that dispossession is going to entail more than the physical removal of material objects. Fromm (1976) posed the problem this way: "If I am what I have and what I have is lost, who then am I?"

\section{Why Dispossession?}

It next seems straightforward to predict that people will release a thing from their stores when all motives for its possession have been extinguished, in which case the labor of possession is not worth the effort. The thing is no longer valuable or delightful or carries the past. Alternatively, reasons for keeping may remain intact but the labor of possession becomes unsustainable-too costly in terms of time, money, or effort. So, possessions endure as such so long as motives for possession match or exceed the labor of possession. That is, motive $\geq$ labor. When the balance tips, the thing is a candidate for dismissal (Roster, 2001).

But it is only a candidate. The suddenly problematic status of not worth keeping may lead to a re-imagination of motive, i.e., the accentuation of yet another reason for keeping. I think that one could test the idea that possession motives \#2 (worth money) and \#8 (someone could use this) are the residual, last-resort rationales for hanging onto something that has lost all other purpose. I have long kept my late father's coin collection out of loyalty to his memory and an affirmation of our common boyhood occupation as newspaper carriers. But the coins' safekeeping gives me anxiety and I presently think that I keep them mainly for their value (which I plan to explore someday). Alternatively, the not-worth-keeping status could lead to the search for more possession resources-more space, help with maintenance, a lock box for those coins.

Next, pushing the question further, what might upset the relation [motive $\geq$ labor] and so set off the prospect of dispossession? I suggest three circumstances. 
First, there are exogenous threats to possession that arise from natural and social sources. Things can rot, crumble, rust, wear down, or die, thus ruining their practical or emotional value. Things can be devastated by fire or smoke, violent breakage, water or mold, or vermin. Theft can remove possessions, and not only by burglary. We have met adult children who, believing that their parents have excess belongings, will take it upon themselves to trash things behind the elder's back. Items are also removed when possession is contested, for example, when property is divided during a divorce, or when goods enjoy familial ownership and another kin member claims a turn at possession. Dispossession by all of these exogenous means is involuntary and irretrievable. The things simply become functionally unavailable.

The second circumstance that puts possessions in doubt is some sort of failure with their capacity for social mediation. Goods, according to Douglas and Isherwood (1980), are the visible part of culture, vehicles of communication and membership. Yet they may someday fail to supply the information that we need for daily social commerce or the sentiment that sustains group or kin membership. We may find that they no longer represent our interests, identity, or rank, or they invite negative social judgments. We maintain clothing, utensils, machinery, furnishings, leisure goods, decorations, rooms, buildings, and yards. We may not have acquired all these things purely for purposes of strategic display, but display they do. They put our selves forward, presenting our persons as commodities to be regarded by others (Bauman, 2007). And if we sense that these things tell our story in an adverse way (e.g., we are out of fashion by some standard) it puts possession motives up for review. In my household, we have forsaken entertaining with our smallish, crystal wine glasses in favor of new flute- and globe-shaped stemware that is the current standard for serving white and red wine. Those old glasses-once wedding gifts-are no longer "us."

Social judgment about excess possessions-materialism-is the prompt for adults' periodic, voluntary campaigns at clutter reduction. The moral charge of "too much" is directed more at volume rather than specific objects. The downsizing imperative-a staple of popular media-has given rise to an entire industry that, 
hilariously, is another form of consumption. According to a recent news report, U.S. sales of home-organization products will rise to $\$ 7.6$ billion by 2009 . Closet-organizing systems are already a $\$ 3$ billion-a-year business. There is even a National Association of Professional Organizers, 4,000 members strong (Green, 2006). The ability of capitalism to commodify anything, in this case disconsumption, should never be doubted.

Life course change is the third circumstance inviting dispossession. Because we acquire and keep goods in order to fulfill social roles, it follows that role relinquishment might be the occasion to revisit possession motives. For example, work roles compel the acquisition of specialized clothing, tools, transportation, and self-care materials. Upon changing jobs, these materials may need to be refreshed. The successive stages of child rearing might lead to the relinquishment of goods and furnishings used to support infancy, then childhood, then youth. My home was once ankle deep in toys and playthings, of which only a residual few remain in a box in the closet, for visitors. Not only motives but also the labor of possession could come in for review due to role changes of the life course that divert time and money to other purposes.

Role change and moving on can leave some possessions not only functionally irrelevant but also negatively charged if former stages of life are now seen as undesirable. Disposition of belongings, though usually portrayed as a difficult process of detachment from self (Young and Wallendorf, 1989) can in some circumstances be a welcome occasion to push away possessions that are extensions of an undesired self (Lastovicka and Fernandez, 2005).

Concurrent with another kind of life course change, the labor of possession can become untenable with disability or with the normative narrowing of the life-world that occurs in later life. My colleagues and I have studied the particular instance of household disbandment when elders choose, or are forced to live in, smaller quarters where they cannot house all their things. Sometimes the downsizing is undertaken to anticipate life change, such as a move to care or even death. We know elders who have thinned their things in order to free adult children from any posthumous burden 
of excess possessions, or to protect their legacy from the judgment that they had had too much stuff. Though downsizing in later life appears as a surrender to age-related vulnerability, such "selection" of more manageable housing can be a positive, gratifying step (Marsiske et al., 1995).

\section{Outplacement}

The unbalanced relation [motive $\geq$ labor] is only the occasion for the dispossession of material. Next comes the act itself (Roster, 2001) and what might be called the labor of dispossession. The general term for this is disposal or, in its less latinate, more current version, "outplacement." The work of keeping is now weighed against the work of not keeping.

Our studies of older movers found a hierarchy of disposition strategies that people used during the short episodes of household disbandment. Of the possessions not intended for retention, people first made gifts of selected things. Then they attempted to sell other things, donating yet other things (some of which had been unsalable) and discarding another batch that had fallen into residual status. A single item might be subject to more than one disposal strategy. During this process, the meaning of things is tested and revised. These same strategies are available for any act or campaign of dispossession at any age, but not necessarily in the sequence that we observed during these intense downsizings. Gift giving is probably not a primary strategy among young and middle-aged adults. Given the secular trend toward larger dwellings, dispossession is likely to be voluntary until later life.

Gifts are fraught with calculation. The giver must imagine the appropriate possession relation [motive $\geq$ labor] in the receiver: that the receiver will find it useful, pleasing, or bonding to the giver; that the receiver can accommodate it or animate it (give it a "good home") as the possessor has. The timing of the transfer (the right occasion) must be planned, and there must be an eye to feelings of inequity among other potential recipients (Stum, 1999). The red leather gloves in my bedside table belonged to my late mother. They would be a perfect gift for my oldest daughter, but I have no comparable gift for my other daughter. So, for now, I continue to 
store the gloves. The significant risk in gift giving is that the receiver will not want the thing. If belongings that are invested with one's identity do not find heirs or interest among kin or friends, the failure to place them can be a source of grief (Marcoux, 2001; Marx, Solomon, and Miller, 2004).

A common reason for gift-rejection in intergenerational giving-older to younger-is that the recipient's household is already provisioned with the thing or that tastes in the thing are not mutually shared. For example, the possession of "fine things" such as china, silver service, and crystal glassware has been seen as the mark of domesticity among the current cohort of older women (Blaszcyk, 2000) but we hear now that the daughter generation does not welcome such "impractical" objects.

Sales to strangers are also a risk to the meaning that the possessor has invested in a belonging (Lastovicka and Fernandez, 2005; Price, Arnould and Curasi, 2000). The buyer's ability to undertake the labor of possession is not the seller's concern, but the seller's concept of the item's monetary value is about to be tested as the possession returns to being what it once was, a commodity in a marketplace. There is effort in getting the thing to market; it must be made presentable and then actually presented, even if only out to the street. Agents, such as antique dealers or online auction sites, can relieve some of the sale-related labor, but there is nevertheless effort (paying fees, acquiring know-how) in engaging these gobetweens. Interpersonal sales sometimes shade toward gift giving when the seller, sensing that the buyer's possession motives might be aligned with his or her own, cuts the price so as to guarantee the item's placement (Herrmann, 1997).

Donation - to community agencies, churches, veterans groups, arts organizations, libraries, museums, historical societies, humane societies-is also not without the labor of presentation and interaction with outside parties. In the US, such deposits are tax-deductible and so the goods' monetary value can be affirmed if only in a token way. Beyond convenience, donation has aspects akin to gift giving when owners place their things strategically to assure a continuity of appreciation and values, what Roster (2001) calls "safe passage." 
Donation, as noted, can take effort and expense. Many an American household has bookshelves groaning with a hoard of golden yellow National Geographic magazines. What can be done with them? When an American soldier requested that people send their collections to children in Afghanistan, the response was generous. But some donors reportedly "backed off when they found that it would cost them $\$ 8$ to send a box of 30 or so issues. Most opted to keep their magazines stockpiled" (Alcalá, 2007).

To discard might once have meant tipping things over the fence, down the ravine, or into the woods. No more. I can still burn things, bury them, and send them down the drain with minimal effort, but the rest of my trashing involves sorting and presenting (Hetherington, 2004). My municipal waste (limit: two bags per week) must exclude yard trimmings and leaves, recyclables, hazardous materials, and large bulky items. All of these categories have their own separate procedures for disposal, some of which I must contract out to others. If the rigmarole of rubbishing does not give one pause, then emotions may when facing the finality of disposal. Some people draw out the disposal process by placing doomed items in provisional exile at the margin of the household (e.g., the garage) later giving them final disposal when their ambivalence has been resolved (McCracken, 1988).

Even after possessions have left one's control, they may not be wholly gone, instead exerting an "absent presence" (Hetherington, 2004). As I have noted, people can continue to imagine the possible afterlife of things that they have given, sold, or donated away. Even with their garbage, they can perhaps take pleasure in thinking that recycling efforts have rescued items of trash for further use. The afterlife of gifts, however, does not need to be imagined; gifts can actually be visited to check whether the thing's new circumstances remain suitable. Perhaps this is why adult children refuse gifts from parents, because they do not want the responsibility of curating someone else's collection of stuff.

In summary, possessions are consumption items that stay long enough to merit some care, if only to be merely placed somewhere for later consideration. Across time, mixed and shifting motives for possession must match or exceed the labor of keeping them. 
When the balance tips, there is still labor in the outplacement effort. Keeping or releasing, there is always work to do. The placing of things is the responsibility of consumption, and it sometimes seems a curse.

Things are tenacious-in the root meaning of that word, they "hold fast." Or seem to. It is we who are tenacious, because the bonds we create with our things are a "continuous creation" (Sartre, 1956) and those bonds are constitutive of identity. Dispossession, then, is nothing less than an encounter with our selves. Which is why downsizing and decluttering are not readily delegated to others-spouse, family members, appraiser, or the 4,000 members of the National Association of Professional Organizers-until the tenacious self allows.

\section{Note}

1. This research was supported by grants from the National Institute on Aging, AG19978 and AG30477.

\section{References}

Alcalá, C. (2007, July 19). "Magazine's shelf life has no boundaries.” Sacramento Bee: B1.

Appadurai, A. (1986). The social life of things. New York: Cambridge University Press.

Bauman, Z. (2007). Consuming life. Malden, MA: Polity Press.

Belk, R.W. (1988). "Possessions and the extended self." Journal of Consumer Research, 15: 139-168.

Blaszczyk, R.L. (2000). Imagining consumers: Design and innovation from Wedgwood to Corning. Baltimore, MD: Johns Hopkins University Press.

Brower, S., \& Guthrie, N. (2005). Woody Guthrie artworks. New York: Rizzoli.

Brown, B. (2004). "Thing theory," in B. Brown (Ed.), Things. Chicago: University of Chicago Press.

Csikszentmihalyi, M., \& Rochberg-Halton, E. (1981). The meaning of things: Domestic symbols and the self. New York: Cambridge University Press.

Curasi, C.F., Price, L.L., \& Arnould, E.J. (2004). "How individuals' cherished possessions become families' inalienable wealth.” Journal of Consumer Research, 31: 609-622.

Dant, T. (1999). Material culture in the social world: Values, activities, lifestyles. Philadelphia: Open University Press.

Dittmar, H. (1992). The social psychology of material possessions: To have is to be. New York: St. Martin's Press.

Douglas, M., \& Isherwood, B. (1980). The world of goods. New York: Basic Books.

Dudley, D. (2007, January-February). "Conquering clutter." AARP Magazine: 64-72.

Ekerdt, D.J. \& Sergeant, J.F. (2006). "Family things: Attending the household disbandment of older adults." Journal of Aging Studies, 20: 193-205.

Ekerdt, D.J., Sergeant, J.F., Dingel, M., \& Bowen, M.E. (2004). "Household disbandment in later life." Journal of Gerontology: Social Sciences, 59B: S265-273. 
Fromm, E. (1976). To have or to be? New York: Harper \& Row.

Furby, L. (1978). "Possession: Toward a theory of their meaning and function throughout the life cycle," in P.B. Baltes (Ed.), Life-span development and behavior, Vol. I (pp. 297-336). New York: Academic Press.

Gosling, S.D., Craik, K.H., Martin, N.R., \& Pryor, M.R. (2005). "The Personal Living Space Cue Inventory: An analysis and evaluation.” Environment and Behavior, 37: 683-705.

Greene, P. (2006, December 21). "Saying yes to mess." New York Times: F1.

Herrmann, G. (1997). "Gift or commodity: What changes hands in the U.S. garage sale?" American Ethnologist, 24: 910-930.

Hetherington, K. (2004). "Second-handedness: Consumption, disposal and absent presence." Environment and Planning D: Society and Space, 22: 157-173.

Kleine, S.S., \& Baker, S.M. (2004). "An integrative review of material possession attachment." Academy of Marketing Science Review, 2004, (1). Retrieved April 25, 2008 from http://www.amsreview.org/articles/kleine01-2004.pdf.

Kleine, S.S., Kleine, R.E., \& Allen, C.T. (1995). "How is a possession 'me' or 'not me'? Characterizing types and an antecedent of material possession attachment." Journal of Consumer Research, 22: 327-343.

Lastovicka, J.L., \& Fernandez, K.V. (2005). "Three paths to disposition: The movement of meaningful possessions to strangers." Journal of Consumer Research, 31: 813-823.

Lucas, G. (2002). "Disposability and dispossession in the twentieth century." Journal of Material Culture, 7: 5-22.

Marcoux, J-S. (2001). "The 'casser maison' ritual: Constructing the self by emptying the home." Journal of Material Culture, 6: 213-235.

Markus, H., \& Nurius, P. (1986). "Possible selves." American Psychologist, 41: 954969.

Marsiske, M., Lang, F.R., Baltes, P.B., \& Baltes, M.M. (1995). "Selective optimization with compensation: Life-span perspectives on successful human development," in R.A. Dixon \& L. Bäckman (Eds), Compensating for psychological deficits and declines: Managing losses and promoting gains (pp. 35-79). Mahway, NJ: Erlbaum.

Marx, J.I, Solomon, J.C., \& Miller, Lee Q. (2004). "Gift wrapping ourselves: The final gift exchange." Journal of Gerontology: Social Sciences, 59B: S274-S280.

Mauss, M. (1990). The gift: The form and reason for exchange in archaic societies. New York: W.W. Norton.

McCracken, G. (1988). Culture and consumption: New approaches to the symbolic character of consumer goods and activities. Bloomington, IN: University of Indiana Press.

O’Brien, M. (1999). "Rubbish-power: Towards a sociology of the rubbish society," in J. Hearn \& S. Roseneil (Eds.), Consuming cultures: Power and resistance. New York: St. Martin's Press.

Price, L.L., Arnould, E.J., \& Curasi, C.F. (2000). "Older consumers' disposition of special possessions.” Journal of Consumer Research, 27: 179-201.

Richins, M.L. (1994). "Valuing things: The public and private meanings of possessions." Journal of Consumer Research, 21: 504-521.

Riley, MW, Foner, A., \& Waring, J. (1988). "Sociology of age," in N.J. Smelser (Ed.), Handbook of Sociology (pp. 243-290). Newbury Park, CA: Sage.

Roster, C.A. (2001). "Letting go: The process and meaning of dispossession in the lives of consumers," in M.C. Gilley and J. Meyers-Levy (Eds.), Advances in consumer research, Vol. 28 (pp. 425-430). Provo, UT: Association for Consumer Research. 


\section{Consumption and Generational Change}

Sartre, J. P. (1956). Being and nothingness (H. Barnes, Trans.). New York: Washington Square Press.

Stum, M.S. (1999). "'I just want to be fair': Interpersonal justice in intergenerational transfers of non-titled property." Family Relations, 48: 159-166.

Thompson, M. (1979). Rubbish theory: The creation and destruction of value. New York: Oxford University Press.

U.S. Environmental Protection Agency. (2008). Municipal solid waste in the United States. 2006 facts and figures. Retrieved April 25, 2008 from http://www.epa.gov/ garbage/mswpp.htm.

Young, M.M., \& Wallendorf, M. (1989). "'Ashes to ashes, dust to dust': Conceptualizing consumer disposition of possessions," in T.L. Childers, R.P. Bagozzi, \& J.P. Peter (Eds.), Proceedings of the American Marketing Association Winter Educators Conference (pp. 33-39). Chicago: American Marketing Association. 


\title{
Consumption and Generational Change
}

\author{
The Rise of Consumer \\ Lifestyles
}

\section{Ian Rees Jones, Paul Higgs, and David J. Ekerdt, editors}

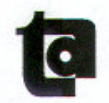

Transaction Publishers

New Brunswick (U.S.A.) and London (U.K.)

Copyright $\odot 2009$ 


\section{Contents}

Foreword

vii

Frank Trentmann

Preface

xiii

1. Consumption and Generational Change: 1 The Rise of Consumer Lifestyles

Ian Rees Jones, Paul Higgs, and David J. Ekerdt

\section{Part I: Theoretical Perspectives on Generations and Consumption}

2. The Third Age: Field, Habitus, or Identity?

Chris Gilleard and Paul Higgs

3. Goods Not Gods: New Spiritualities, Consumerism, and Religious Markets

Bryan S. Turner

4. Dispossession: The Tenacity of Things

David J. Ekerdt

\section{Part II: Historical Dimensions of Generation and Consumption}

5. Old Age, Consumption, and Change over Time Pat Thane

6. Ageing, Cohorts, and Consumption: The British Experience 1968-2005

Martin Hyde, Paul Higgs, Chris Gilleard,

Christina Victor, Dick Wiggins, and Ian Rees Jones 
Part III: International Comparisons of Changes in Consumption

Patterns across Generations

7. Housing Crisis, Generational Inequalities, and Welfare States

Fanny Bugeja

8. Generational Marketing

George P. Moschis

9. Comparing Welfare Regime Changes:

171

Living Standards and the Unequal Life Chances

of Different Birth Cohorts

Louis Chauvel

About the Contributors 